\title{
Steyskalina picta, new genus and species of Tetanocerini (Diptera, Sciomyzidae) from the Oriental Region
}

\author{
Kumar Ghorpadé ${ }^{1}$ \\ Luciane Marinoni $^{2}$ \\ Lloyd Knutson ${ }^{3}$
}

\begin{abstract}
A new genus, Steyskalina Knutson, is erected for S. picta Ghorpadé \& Marinoni, an undescribed species of the Sciomyzidae, Tetanocerini, discovered from Burma and the neighbouring Yunnan Province of China. The habitus and male terminalia are illustrated. Comments about the affinities of the genus within the Tetanocerini are also included.

KEY WORDS. Tetanocerini, Sciomyzidae, Steyskalina picta, new genus and species, Burma, China
\end{abstract}

While preparing a comprehensive taxonomic revision of the Sciomyzidae of the Oriental Region, Knutson \& Ghorpadé recognized a new genus and species of Tetanocerini from a male and a female collected in the Shan States of Burma (Myanmar in native tongue), which the former had discovered in the Naturhistoriska Riksmuseet [NRS], at Stockholm (Sweden), in 1963. Recently, Luciane Marinoni found and studied a further 2 males and 1 female of this new taxon which were collected in 1985 from K'un-ming in the Yünnan Province of China, across the border from Burma, in the collections of the National Museum of Natural History [USNM], Washington, D.C.

It has become a matter of some urgency, to make the new names available to Science, since Luciane Marinoni and Wayne Mathis (Smithsonian Institution, Washington, D.C., U.S.A.) have a paper on a computer-based cladistic analysis of Sciomyzidae in press.

Steyskalina Knutson is the only endemic Sciomyzidae genus known from the Oriental Region, from where a further 10 genera have been identified by Knutson \&Ghorpade.

1) 1861 Bethel Street, Bangalore 560 043, India.

E-mail: varanus.kg@mailcity.com

2) Departamento de Zoologia, Universidade Federal do Paraná. Caixa Postal 19020, 81531-990 Curitiba, Paraná, Brasil.

E-mail: Imarinon@bio.ufpr.br

3) 4 rue des Erables, 34830 Clapiers, France.

E-mail: Ivknutson@wanadoo.fr 


\section{Steyskalina Knutson, gen.n.}

Type-species: Steyskalina picta Ghorpade \& Marinoni, sp.n. (here designated).

Description. Face almost perpendicular, slightly receding; lunule mostly covered, only slightly exposed between antennal bases; without shiny midfrontal stripe, but with entire frons pruinose; area between ocellar triangle and anterior margin of frons with brownish-black spot; ocellar setae well developed; arista with long black hairs; proepisternum without seta, with 4-7 small hairs; no vallar (subalar) setae; 1 unusually strong seta at upper middle of katepisternum (this seta on both sides of all specimens), with a peculiar bend not seen in thoracic setae of any other Sciomyzidae; pedicel with 2 long setae on dorsal margin near apex; 2 pairs of scutellar setae (one pair basal and one pair subapical); no hairs on posterodorsal margin of hind coxa; hind tibia with 1 anterodorsal pre-apical seta; wing with dense pattern; cup truncate apically; posterior crossvein not curved; male terminalia with epandrium closed posteroventrally below cerci; posterior pair of surstyli well developed and anterior pair absent; reduced fifth sternum symmetrical; combined sixth and seventh sterna strongly asymmetrical.

Diagnosis and Discussion. Steyskalina is a member of the Tetanocerini as indicated by the lack of a proepisternal seta (present in the genera Shannonia Malloch, 1933 and Perilimnia Becker, 1919 of the Tetanocerini) but the presence of 4-7 small hairs in this location (Fig. 1); cup truncate apically; no median setae on mid or hind tibiae; and male postabdomen with 1 well developed pair of surstyli (posterior), and the absence of the anterior pair. At first glance this genus resembles two Tetanocerini genera: Euthycera Latreille, 1829 and Dictya Meigen, 1803. Morphological similarities with Euthycera are the patterned wing; 2 strong setae on pedicel; well developed ocellar and fronto-orbital setae; no vallar setae; no hairs on posterodorsal margin of hind coxa; 2 pairs of scutellar setae; and male terminalia with asymmetrical, combined sixth and seventh sterna. Euthycera differs from Steyskalina in having the lunule broadly exposed; short white aristal hairs; a shiny midfrontal stripe; and epandrium not closed below the cerci. Dictya also resembles Steyskalina somewhat, except that Dictya has a median black spot on the face and, although having small katepisternal hairs, lacks a katepisternal seta; the anepisternum and anepimeron of Steyskalina are bare (Fig. 1), whereas Dictya has strong anepimeral and anespisternal setae, besides having many other differing characters.

The above comparisons of genera indicate relationships on an intuitive basis. In the computerized cladistic analysis of MARINONI \& MATHIS (in press), Steyskalina appears in a polytomy with Euthycerina Malloch, 1933, Tetanocera Duméril, 1800, Trypetolimnia Mayer, 1953 and Psacadina Enderlein, 1939. Steyskalina shares with Tetanocera, Trypetolimnia and Psacadina the presence of one pair of surstyli (the posterior) and with Tetanocera and Guatemalia Steyskal, 1960 the epandrium closed below the cerci. Tetanocera is a New World and Holartic genus, with a single species (T. chosenica Steyskal, 1951) known also from southern China in the Oriental Region. Psacadina and Trypetolimnia are Paleartic endemic while Euthycerina and Guatemalia are Neotropical ones.

Distribution. Endemic to the Oriental Region. Known only from Burma and China (Yunnan). 
Remarks. Nothing is known about the biology of this new species. The former take the opportunity to name this new genus in honor of one of the premier students of acalyptrate Diptera, the late, George C. Steyskal.

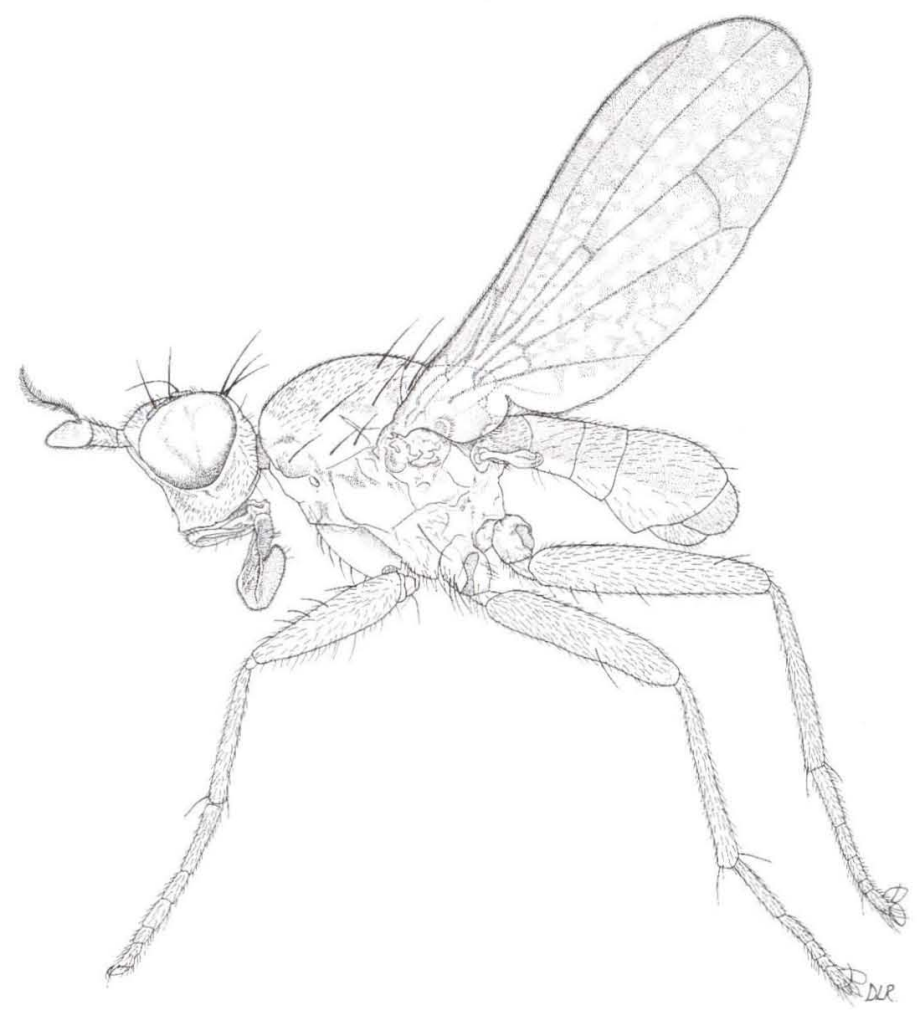

Fig. 1. Habitus of Steyskalina picta Ghorpadé \& Marinoni, sp.n., left lateral view.

\section{Steyskalina picta Ghorpadé \& Marinoni, sp.n.}

Figs 1-9

Male and Female. Head: frons mainly shiny, iridescent yellow, with broad median brown stripe from occiput over ocellar triangle to lunule; narrow orbital margins also brown, white pruinose; 1 pair of long ocellar setae; 1 pair of proclinate fronto-orbital setae; 1 pair of reclinate fronto-orbital setae; 1 pair each of postocellar, vertical and postvertical setae; small hairs along orbits, especially on anterior margin of frons. Occiput brownish grey with brown middorsal stripe continuing from frons, with generally medium sized black hairs laterally. Face and gena pale yellow with dense white pruinosity, gena with several thin, black hairs uniformly over surface. Antenna shorter than width of head (lateral aspect), orangish yellow with irregular brown darkening. Flagellomere as long as scape and pedicel together. Pedicel with 
black spinules and 2 longer suberect hairs dorsomedially; arista orangish brown, brownish black apically, black plumose, the hairs fairly long; arista almost as long as antenna. Eye essentially round, with larger facets anteriorly (especially in male). Palpus yellow. Labellum brownish yellow. Thorax: brown, grey pruinose with indistinct brown middorsal stripe, wholly black setose. Chaetotaxy: 1 pair of humeral setae, 2 notopleurals, 1 presutural, 1 supra-alar, 1 postalar, 2 dorsocentrals, and 2 pairs of scutellars. Scutellum grey with brown median stripe. Pleuron light brown, densely grey pruinose, with a few short black hairs on proepisternum and many longer hairs on katepisternum. Katepisternum with 1 long strong seta with peculiar bend in middle, located near posterodorsal margin, several long setae on lowest corner. Prosternum with 4 hairs on each side. Abdomen: brown, with anterior $1 / 3$ of each tergum greyish, uniformly black setose. Male terminalia as in Figs 2-9. Postabdomen asymmetrical. Sixth sternum free, asymmetrical, well developed on left side. Epandrium well developed, closed below cerci. Synsternum $7+8$ present bearing seventh spiracles. Posterior surstylus symmetrical, well developed, with hairs and with apex hooklike. Anterior surstylus absent. Hypandrium bare, symmetrical. Paramere well developed and very long, without setae. Aedeagus well sclerotized and very complex as in Figs 6-8. Distiphallus asymmetrical. Aedeagal apodeme elongate. Ejaculatory apodeme longer than half length of aedeagal apodeme (Fig. 6). Legs: yellowish brown, black setose. Coxae with greyish pruinescence. Femora with brownish basal, postmedian and apical annuli; fore coxa with 2 depressed setae at apex, followed by 4 suberect setae dorsally and 3 to 4 long erect hairs ventrally; mid femur with distinct anteromedian seta; ventral surface of hind femur with 2 rows of strong, spiny setae; tibiae with apices broadly dark brown. Tarsi with 2 apical segments dark brown, pulvilli yellowish white. Wing: suberect seta on base of costa. Membrane brown with 3 large, subquadrate white spots in apical $2 / 3$ of cell $\mathrm{r} 1$, rest of wing densely patterned with white spots of various sizes, 1 large subquadrate white spot on apex of cell $\mathrm{r} 2+3$. $\mathrm{R}$ ending basad of crossvein $\mathrm{r}-\mathrm{m}$ which is well beyond middle of discal medial cell. Anal vein reaching wing margin. Halter white, base slightly pale brownish. Squama and squamal ciliae yellowish white.

Specimens examined. Five ex. ( 3 males, 2 females). Holotype male labelled: /S. SHAN States, Road 40km E. Taunggyi, 25.IX-13.X.34, Malaise/, and /HOLOTYPE, Steyskalina picta Ghorpadé \& Marinoni 1999/ [Deposited in NRS]. Paratypes 2 males, 2 females: 1 female with same data of holotype and yellow label /PARATYPE, Steyskalina picta Ghorpadé \& Marinoni 1999/ [Deposited in NRS]; 2 males, 1 female labelled /China, Yunnan, 9km S KUNMING, 1 km S Bamboo Temple, 11.IX.1985, 2200-1300m/; /wet meadow in deciduous forest/ and yellow label /PARATYPE, Steyskalina picta Ghorpadé \& Marinoni 1999/ [Deposited in USNM].

Distribution. Burma, China (Yunnan). Confined to the biogeographical subarea of Shan States - Yunnan in the Indo-Chinese Subregion of the Oriental Region.

Remarks. Diagnostic details and comparison with purportedly related taxa are given in the generic diagnosis and discussion above. The flight period observed is from September to October. 


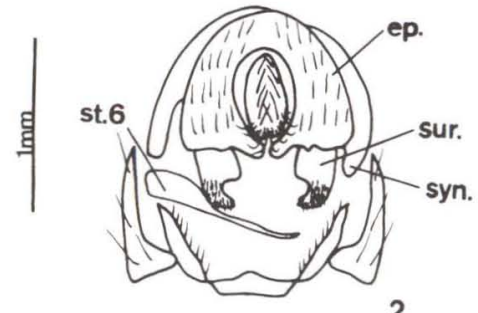

2

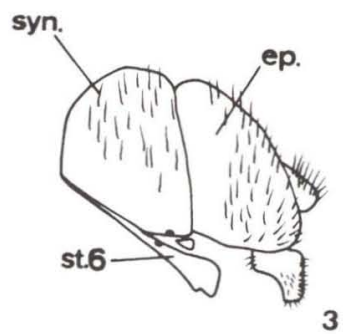

3

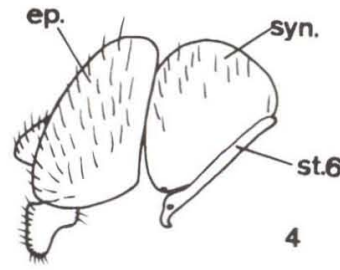

4

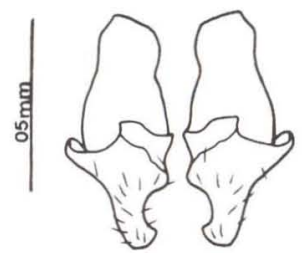

5
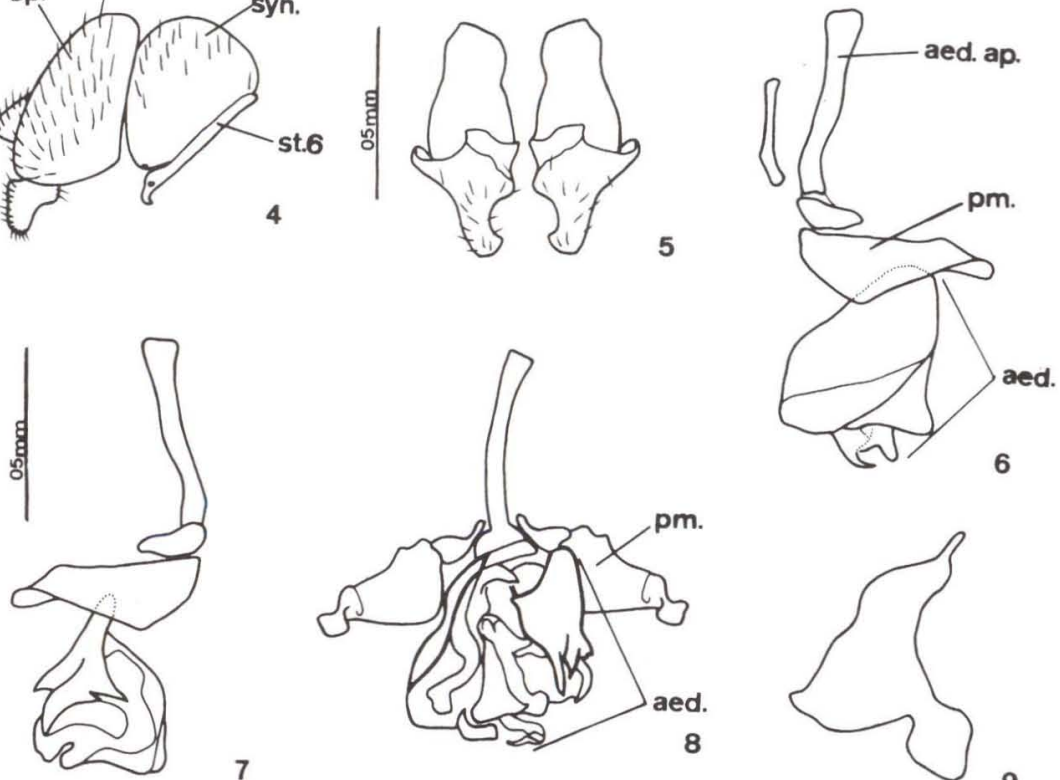

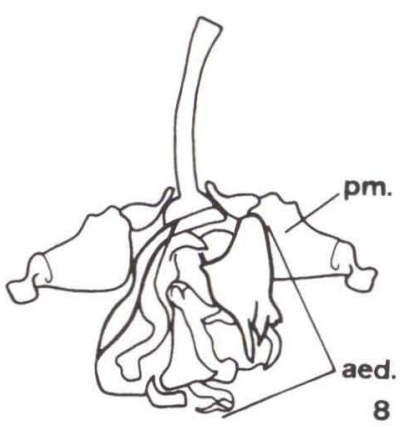

8

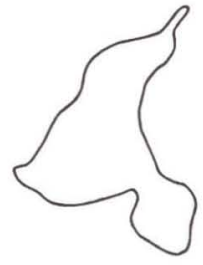

Figs 2-9. Steyskalina picta Ghorpadé \& Marinoni, sp.n.. (2-4) Male postabdomen: ventral, left lateral and right lateral views; (5) posterior surstyli: dorsal view; (6-8) male genitalia: left lateral, right lateral and dorsal views; (9) hypandrium, left lateral view. (Aed.) Aedeagus, (Aed. Ap.) aedeagal apodeme, (Ep.) epandrium, (Pm.) paramere, (St. 6) sternum 6, (Sur.) surstyli, (Syn.) synsternum $7+8$.

ACKNOWLEDGEMENTS. We are grateful to Dr. Wayne N. Mathis (USNM) and Dr. P.I. Persson (NRS) for providing the examined specimens and to Deborah L. Roney for preparing the habitus figure.

\section{REFERENCES}

MARINONI, L. \& W.N. MATHIS (in press). Cladistic analysis of Sciomyzidae Fallén, 1820 (Diptera). Proc. Biol. Soc. Wash..

Recebido em 22.V.1998; aceito em 26.VIII.1999. 